\title{
Probe-based confocal laser endomicroscopy (pCLE) images of submucosal growth of a duodenal mucous neck cell adenoma
}

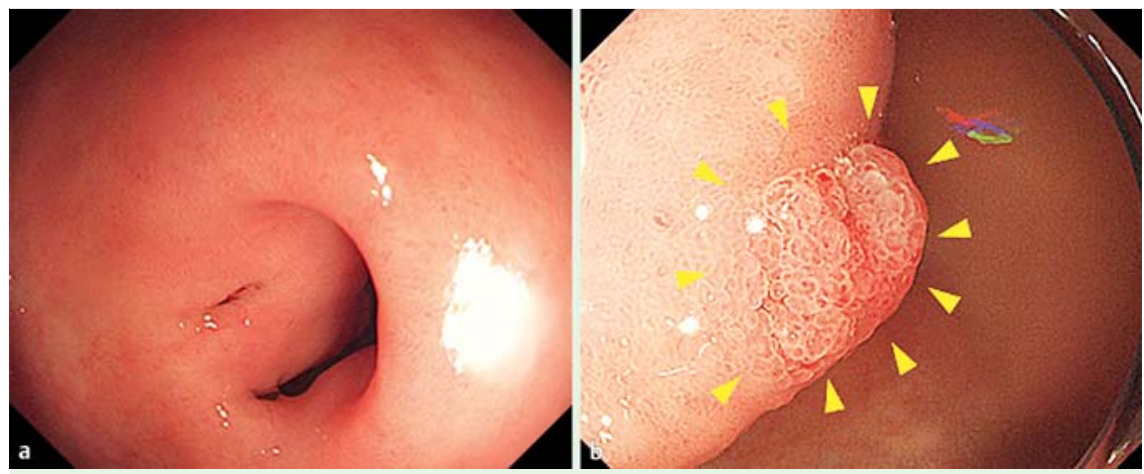

Fig. 1 Gastroduodenoscopy images showing: a a 1.5-cm submucosal elevation with a small depression in the duodenal bulb beneath the pyloric ring; $\mathbf{b}$ a $3-\mathrm{mm}$ protruding lesion on top of the submucosal elevation.

Probe-based confocal laser endomicroscopy ( $\mathrm{pCLE}$ ) is an imaging technique that provides in vivo and real-time endomicroscopic analysis $[1,2]$. We show images of a duodenal mucous neck cell adenoma growing in the submucosa that was visualized by pCLE.

A 77-year-old man presented with a 3-mm protruding lesion in the duodenal blub ( $\bullet$ Fig. 1). The lesion was located on top of a submucosal elevation of approximately $1.5 \mathrm{~cm}$ in size with a small depression. The protruding lesion, but not the submucosal elevation, was pathologically diagnosed as an adenoma. Endoscopic mucosal resection (EMR) was initially performed to resect the protruding lesion. However, an endoscopic biopsy from the post-EMR scar detected an adenoma 2 months later. We performed pCLE, inserting the pCLE probe deeply into the small depression as well as the post EMR scar ( $\bullet$ Fig. 2). Fluorescein-aided pCLE scanning demonstrated dark, small, and irregular-shaped crypts in the deep part of the lesion, suggesting growth of an adenoma ( $\mathbf{F i g . 2 d}$, - Fig. 2 e; Video 1) [2]. In contrast,
pCLE scanning of the surface showed regular-shaped villous structures, suggestive of non-neoplastic epithelium covering the lesion ( $\bullet$ Fig. $2 \mathrm{c}$; $\bullet$ Video 2 ).

Hybrid endoscopic submucosal dissection (circumferential cutting followed by snare resection) was performed to achieve en bloc resection of the entire submucosal elevation. Microscopic examination showed submucosal growth of the adenoma ( $\bullet$ Fig.3). Immunohistochemical assessment showed positivity for MUC5AC, MUC6, pepsinogen-I, and pepsinogen-II ( $\bullet$ Fig.4). Because these staining characteristics were consistent with those of mucous neck cells and primitive chief cells of the gastric fundic glands, a diagnosis of mucous neck cell adenoma of the duodenal bulb arising from ectopic gastric mucosa was made.

Mucous neck cell adenomas are rare neoplasms of the stomach and duodenum [3]. The initially resected protruding lesion can be considered to be an epithelial component of the submucosal adenomatous growth. Dark, small, or irregular-shaped crypts on the pCLE scanning reflected the

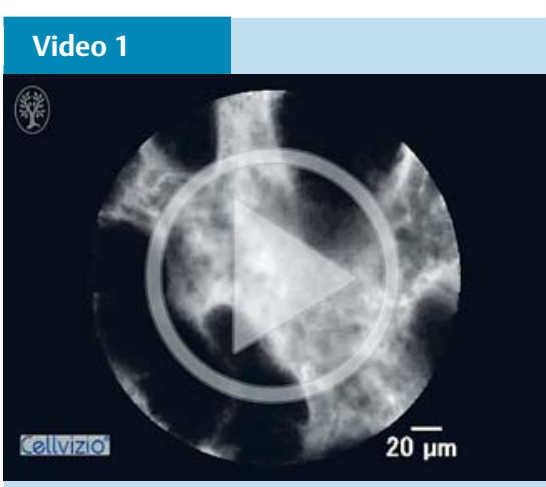

Probe-based confocal laser endomicroscopy ( $\mathrm{pCLE}$ ) scanning with the probe inserted deeply into the small depression showing dark, small, and irregular-shaped crypts.

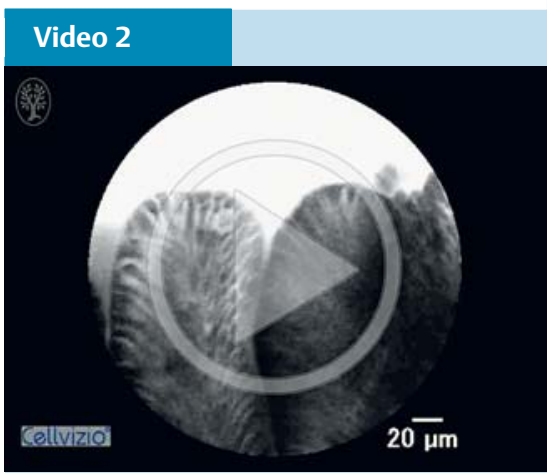

Probe-based confocal laser endomicroscopy ( $p C L E$ ) scanning on the surface of submucosal elevation showing regular-shaped villous structures.

histological features of a submucosal growth of adenomatous tissue, providing useful information when making a decision on therapeutic strategy.

Endoscopy_UCTN_Code_CCL_1AB_2AZ_3AB

Competing interests: None 


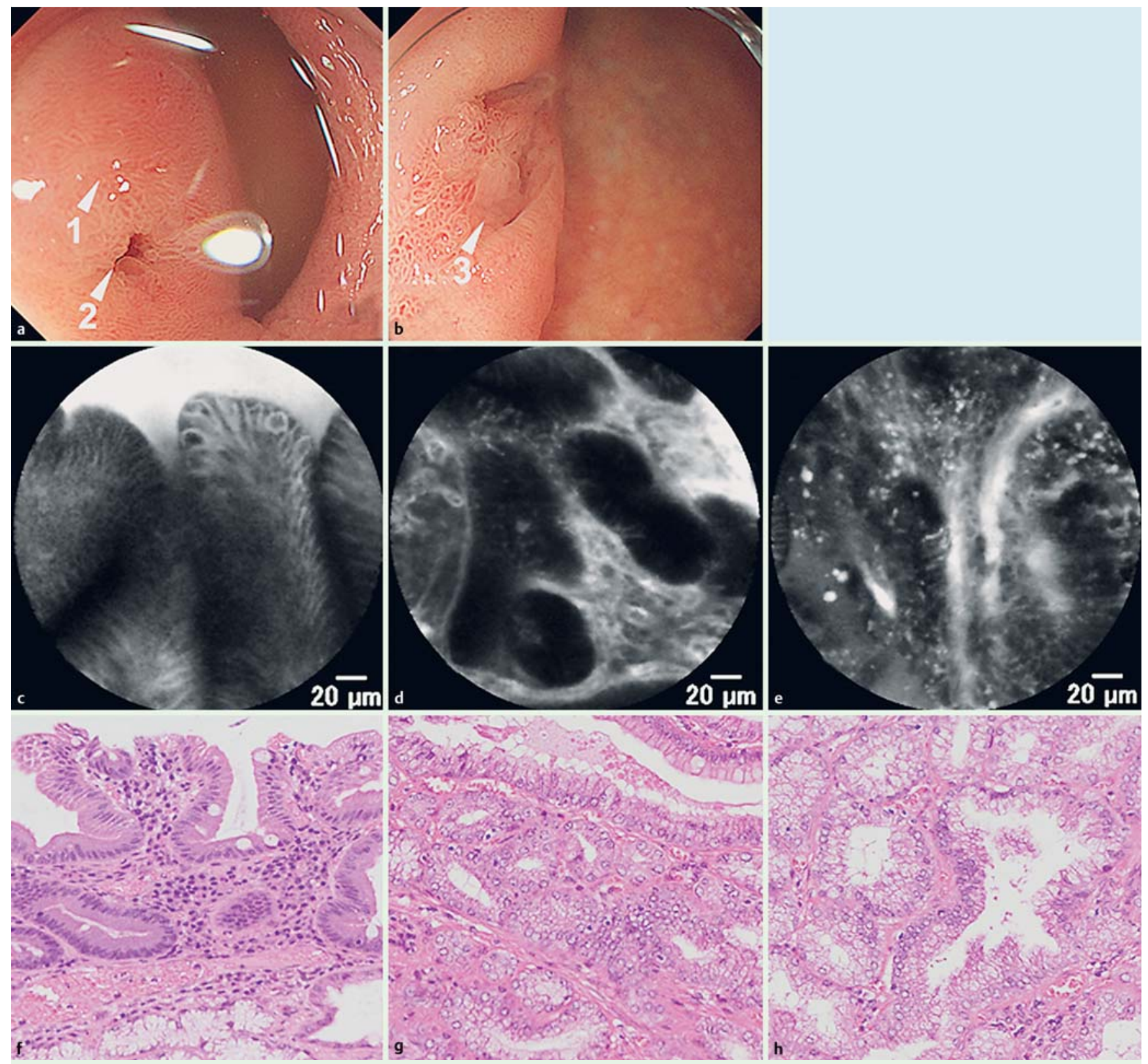

Fig. 2 Comparison of probe-based confocal laser endomicroscopy (pCLE) and histology of the lesion 2 months after endoscopic mucosal resection. a, b Gastroduodenoscopy images with the sites for the PCLE images marked by arrowheads ( 1 , surface of the submucosal elevation; 2 , the small depression; 3 , the post-endoscopic mucosal resection scar). $\mathbf{c}-\mathbf{e}$ Representative PCLE images with the probe at the sites marked by white arrowheads in parts $\mathbf{a}$ and $\mathbf{b}$ showing: $\mathbf{c}$ on surface scanning, regular-shaped villous structures; $\mathbf{d}$, e on deep insertion of the probe, dark, small, and irregular-shaped crypts. $\mathbf{f}-\mathbf{h}$ The microscopic appearances relating to images $\mathbf{c}-\mathbf{e}$, respectively, showing: $\mathbf{f}$ non-neoplastic epithelium covering the lesion; $\mathbf{g}$, $\mathbf{h}$ submucosal adenomatous growth. 

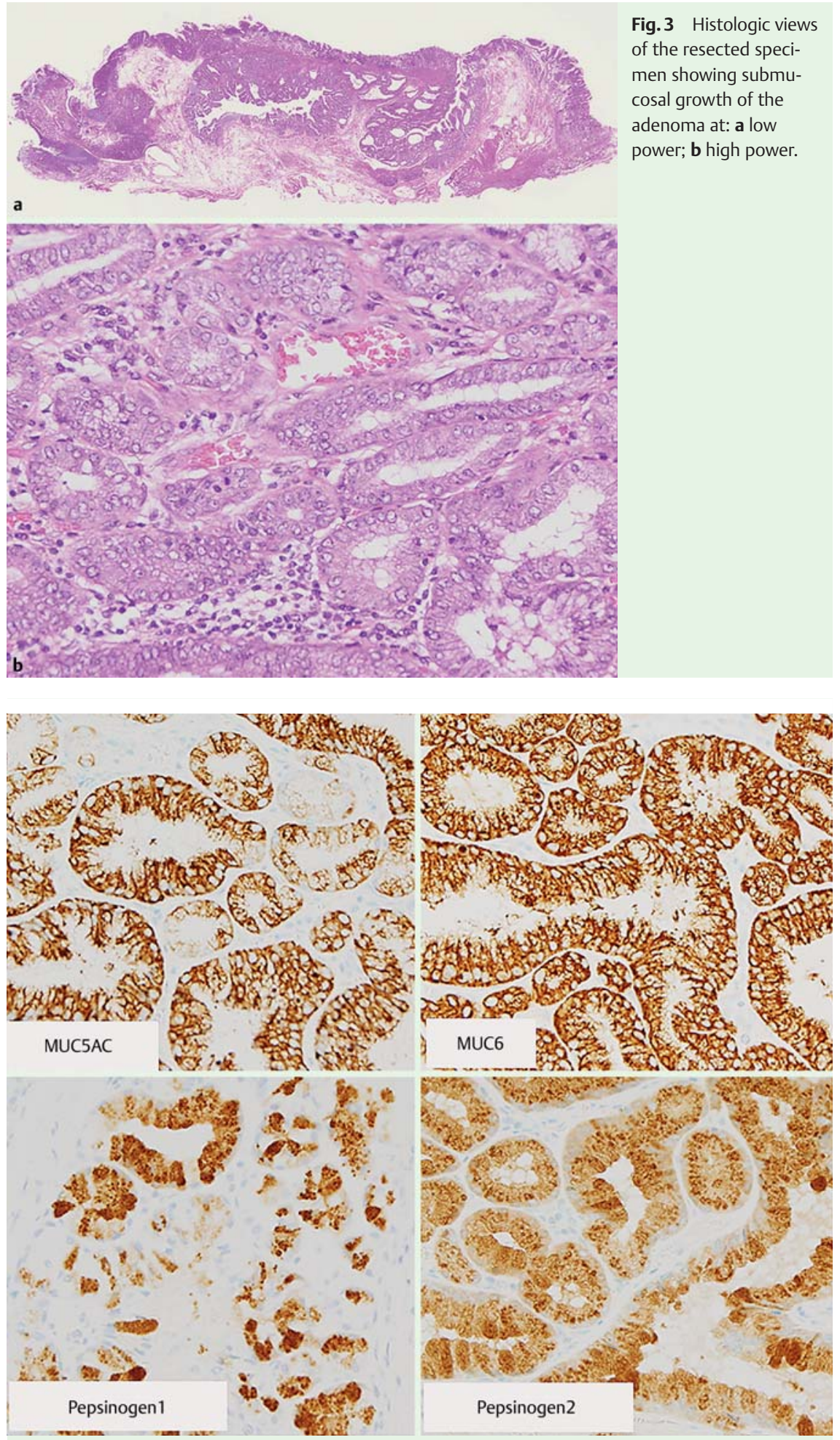

Fig.4 Immunohistochemical analysis showing positivity of the tumor cells for MUC5AC, MUC6, pepsinogen-I, and pepsinogen-II.

\section{Tomomitsu Tahara ${ }^{1}$, Noriyuki Horiguchi', Mitsuo Nagasaka', Yoshihito Nakagawa', Tetsuya Tsukamoto ${ }^{2}$, Tomoyuki Shibata ${ }^{1}$, Naoki Ohmiya ${ }^{1}$}

${ }^{1}$ Department of Gastroenterology, Fujita Health University School of Medicine, Toyoake, Japan

2 Department of Diagnostic Pathology I, Fujita Health University School of Medicine, Toyoake, Japan

\section{References}

1 Neumann $H$, Kiesslich $R$, Wallace $M B$ et al Confocal laser endomicroscopy: technical advances and clinical applications. Gastroenterology 2010; 139: 388-392, 392.e1 -e2

2 Wallace M, Lauwers GY, Chen Y et al. Miami classification for probe-based confocal laser endomicroscopy. Endoscopy 2011; 43: $882-891$

3 Takano S, Otaka M, Miura K et al. A mucous neck cell adenoma of the duodenal bulb arising from ectopic gastric mucosa - a case report [In Japanese]. Gastroenterol Endosc 2012; 54: $2225-2231$

\section{Bibliography}

DOI http://dx.doi.org/

10.1055/s-0041-111031

Endoscopy 2016; 48: E19-E21

(c) Georg Thieme Verlag KG

Stuttgart · New York

ISSN 0013-726X

\section{Corresponding author}

\section{Tomomitsu Tahara, MD}

1-98 Dengakugakubo Kutsukake-cho Toyoake

Aichi, 470-1192

Japan

Fax: +81-562-938300

tomomiccyu@yahoo.co.jp 